\title{
CARACTERIZAÇÃO DE UM SISTEMA DE PRODUÇÃO EM ASSENTAMENTO DE REFORMA AGRÁRIA NO MƯNICÍPIO DE UNAÍ - MG
}

\author{
Erica Campos Riberio ${ }^{1}$ \\ Marcelo Leite Gastal ${ }^{2}$ \\ Thiago Vasconcelos Melo $^{3}$
}

\begin{abstract}
RESUMO
A agricultura familiar no município de Unaí, MG desempenha papel fundamental, pois do total de 3.593 estabelecimentos agrícolas, 2.734 são familiares, correspondendo a $76,1 \%$ do total do município. Este trabalho teve como objetivo identificar e caracterizar os principais sistemas de produção presentes nos assentamentos, além de observar se as informações obtidas possibilitam gerar uma referência para qualificar metodologicamente a prestação de serviço de Assessoria Técnica, Social e Ambiental (ATES). O trabalho foi desenvolvido de outubro de 2013 a fevereiro de 2015 no âmbito de 10 assentamentos da reforma agrária, localizados em Unaí - Minas Gerais, e a metodologia adotada foi a de Diagnóstico Rápido e Dialogado. A elaboração da caracterização possibilitou reconhecer que o meio rural não é homogêneo e é possível fazer uma diferenciação entre os tipos de sistemas. A caracterização é uma importante ferramenta, pois permite conhecer a realidade socioeconômica da família, e propor alternativas tecnológicas compatíveis com os riscos, com a força de trabalho disponível e com os recursos financeiros da família.
\end{abstract}

Palavras-chave: agricultura familiar, desenvolvimento rural, diagnóstico, extensão rural, inclusão social

\section{CHARACTERISTICS OF A SYSTEM OF PRODUCTION IN LAND REFORM IN UNAÍ - MG}

\begin{abstract}
Family farming in the municipality of Unai, MG plays a key role, as the total of 3,593 farms, 2,734 are familiar, corresponding to $76.1 \%$ of the municipality. This study aimed to identify and characterize the main production systems present in the settlements, and see if the information obtained make it possible to generate a reference to methodologically qualify the provision of Technical Advisory Service, Social and Environmental (ATES). The study was conducted from October 2013 to February 2015

\footnotetext{
${ }^{1}$ Graduada em Agronomia (FACTU-Unaí). Especialista em Residência Agrária (UnB). Engenheira Agronomia da Bioflora. E-mail: ericaribeiro.agro@gmail.com

2 Graduado em Agronomia (UFPEL). Mestrado em Sociologia (UnB). Doutorado em Desenvolvimento Sustentável (UnB). Pesquisador da Embrapa Cerrados. E-mail: Marcelo.gastal@embrapa.br

${ }^{3}$ Graduado em Zootecnia (UFRuralRJ). Mestrado em Produção Animal (UENF). Doutorado em Zootecnia (UNESP/FCAV). Professor do Instituto de Ciências Agrárias (ICA) da UFVJM e Docente do Programa de PósGraduação em Estudos Rurais (PPGER) da Universidade Federal dos Vales do Jequitinhonha e Mucuri (UFVJM).
} 
under 10 agrarian reform settlements, located in Unaí - Minas Gerais, and the methodology adopted was the Rapid Assessment and dialogued. The development of characterization allowed to recognize that the countryside is not homogeneous and it is possible to differentiate between the types of systems. The characterization is an important tool because it allows to know the socioeconomic reality of the family, and propose alternative technologies compatible with the risks, with the available workforce and the family's financial resources.

Keywords: diagnosis; family agriculture; rural development; rural extension; social inclusion.

\section{INTRODUÇÃO}

A região do Noroeste de Minas permaneceu até meados do século XX com as características econômicas e sociais herdadas do período colonial, marcada por uma agricultura de subsistência que tem como principal produto econômico a pecuária (MANGGINI, 2012).

A concretização da BR-040 em 1950, ligando a microrregião ao Centro-Oeste do país e à capital Belo Horizonte, a construção da barragem de Três Marias em 1958 e a transferência da Capital Federal para Brasília no ano de 1960 (TORRES, 2000; MANGGINI, 2012) possibilitaram a expansão da fronteira agrícola e o aumento do fluxo migratório de grandes produtores para a região do Noroeste de Minas Gerais. Esse acontecimento, somado ao avanço tecnológico, aceleraram o processo de ocupação do município de Unaí e facilitaram a introdução da revolução verde, cujo pacote tecnológico é fundamentado na monocultura intensiva em mecanização e utilização de insumos e defensivos agrícolas.

Manggini (2012) considera o município um exemplo categórico do desenvolvimento da questão agrária brasileira, pois ao mesmo tempo em que possui o maior PIB Agropecuário (Produto Interno Bruto) do estado, também é líder em desigualdades no meio rural. Do total de 3.593 estabelecimentos agrícolas, 859 propriedades $(23,8 \%)$ detêm 566.809 hectares, o que equivale a $83,3 \%$ do território rural do município. Já a agricultura familiar totaliza 2.734 estabelecimentos, no entanto ocupa apenas $16,6 \%$ do território, correspondente a 113.633 ha. Onde a realidade é marcada pelo grande número de assentamentos de reforma agrária, no total são 34 projetos de assentamento, totalizando 1.639 famílias assentadas.

Apesar do índice de urbanização, as principais atividades econômicas desenvolvidas no município são predominantemente baseadas na agropecuária (Prefeitura Municipal de Unaí, 2013). Do total da área plantada no município (195 mil hectares), 49,3\% (96 mil hectares) é ocupado pelo plantio de soja, posteriormente o feijão ocupa $24 \%$ (48 mil hectares), milho $18,5 \%$ (36.500 hectares) e sorgo representando $6 \%$.

O Estado teve um papel relevante neste processo por meio da implementação de programas de aproveitamento e colonização do Cerrado. Isso ocorreu através de vários planos de desenvolvimento agropecuário regional, como por exemplo o Polocentro e o Prodecer (ambos do Governo Federal); o Planoroeste (do Governo de Minas, voltado para a região noroeste do estado), o PADAp (Programa de Assentamento Dirigido do Alto Paranaíba, também do Governo de Minas) (TORRES, 2000; SOUSA et al., 2011).

Este trabalho teve como objetivo entender o funcionamento dos sistemas de produção existentes, e caracterizar um dos sistemas, possibilitando propor alternativas tecnológicas sustentáveis, além de observar se as informações obtidas 
poderão gerar uma referência de funcionamento de sistema para qualificar metodologicamente a prestação de serviço de Assessoria Técnica, Social e Ambiental (ATES).

\section{REFERENCIAL TEÓRICO}

\subsection{SISTEMAS: PRINCÍPIOS E DEFINIÇÕES}

O ponto de partida do enfoque sistêmico é a ideia de sistema. Cientistas e filósofos há muito tempo trabalham com a ideia de sistema, para ajudar a entender e dar soluções a problemas complexos (MENDONÇA, 2014). A definição de Sistema denota um conceito antigo, originado a partir da palavra grega "Synhistanay", cujo significado é "colocar junto". Apesar de ter-se tornado mais evidente a partir dos anos 50, com aparecimento do fenômeno conhecido como Crise da Ciência (MENDONÇA, 2014). Segundo Pinheiro (2000), esta crise iniciou da preocupação dos cientistas em relação à crescente dificuldade de comunicação entre as várias áreas da ciência, as quais estavam se isolando em "subculturas" cada vez mais específicas.

$\mathrm{Na}$ concepção de Maximiano (1993): "sistema é um todo complexo ou organizado; é um conjunto de partes ou elementos que formam um todo unitário ou complexo". Christofoletti (1979), considerando que os sistemas funcionam executando processos que visam obter determinadas respostas, define o sistema como "conjunto de objetos ou atributos de suas relações, que se encontram organizados para executar uma função particular. " Dessa forma, dentro dessa definição, o sistema é um operador que em um determinado tempo recebe a entrada (input) e o transforma em saída (output).

Baseando-se na definição de Christofoletti (1979), a entrada é composta por aquilo que o sistema recebe, é o alimento do sistema. Por exemplo, a terra recebe energia solar, um animal recebe alimentação. Pode-se exemplificar com outros tipos de entrada como uma fábrica que recebe matéria-prima para sua produção. Cada sistema é alimentado por determinados tipos de entradas. Essas entradas que o sistema recebe sofrem transformações em seu interior e, posteriormente, são enviadas para fora, isso constitui a saída ou output, portanto, toda entrada corresponde a um tipo de saída. compreende:

Na visão de Maximiano (1993), qualquer entendimento da ideia de sistema

Um conjunto de entidades chamadas partes, elementos ou componentes; Alguma espécie de relação ou inserção das partes; A visão de uma entidade nova e distinta, criada por essa relação, em um nível sistêmico de análise.

O próprio enfoque sistêmico é um sistema de ideias. Trata-se de uma preposição consolidada em inúmeras disciplinas, que pode ser caracterizada como filosofia ou forma de produzir, interpretar e utilizar conhecimentos (MAXIMIANO, 1993). Ainda segundo este autor, essa filosofia tem aplicações em todas as áreas da atividade e do raciocínio humano, e também como método de resolver problemas e organizar conjuntos complexos de componentes. 


\subsection{BASES DO ENFOQUE SISTÊMICO}

A ideia de sistema - elementos que interagem e se influenciam, agregados em conjuntos ou todos complexos - é a essência do enfoque sistêmico. É uma ideia relativamente simples, muito embora de grande influência na formação de todos os tipos de profissionais do mundo globalizado. O enfoque sistêmico oferece ao gestor uma visão integrada das organizações e do processo administrativo. É também uma ferramenta para planejar e montar sistemas que produzam resultados (MENDONÇA, 2014).

\subsection{A ORIGEM DO ENFOQUE SISTÊMICO NA AGRICULTURA}

A progressão na direção da visão sistêmica tem acontecido em diversas áreas da ciência, como por exemplo na física, na eletrônica e, inclusive, na agricultura. Nesta área, Pinheiro (2000) afirma que o enfoque sistêmico tem se tornado cada vez mais necessário, em decorrência da crescente complexidade de sistemas organizados e manejados pelo homem e da emergência do conceito de sustentabilidade, o qual lançou novos desafios na área rural.

Neste contexto, a grande maioria dos sistemas agropecuários tem requerido uma abordagem holística e pluridisciplinar, no intuito de melhor serem entendidos e analisados. O enfoque sistêmico tem sido amplamente aplicado no contexto agropecuário principalmente em resposta às crescentes críticas relacionadas aos projetos agrícolas reducionistas e disciplinares direcionados aos pequenos produtores familiares, os quais não têm se beneficiando dos resultados (PINHEIRO, 2000).

Analisando o contexto do surgimento da abordagem sistêmica no ambiente rural e sua posterior introdução neste segmento, Schmitz et al. (2004) salienta que tal fato se deu para melhor analisar a complexidade da agricultura familiar no Terceiro Mundo, mas também nos países industrializados da Europa e outros continentes, e assim, dirigir ações de desenvolvimento mais adequadas à diversidade desta categoria social. No Brasil, a nova abordagem entrou na prática da pesquisa agropecuária a partir da década de 80 , principalmente, através da cooperação francesa (IAPAR, 1993).

O enfoque sistêmico tem sido aplicado em diversas ações de pesquisa, desenvolvimento, ensino e extensão rural. Através do desenvolvimento de vários modelos sistêmicos de pesquisa e extensão em sistemas de produção, a expectativa era de que os resultados destas experiências fossem mais adequados, apropriados e úteis aos pequenos agricultores familiares.

\subsection{ABORDAGEM SISTÊMICA NO ESTUDO DE ESTABELECIMENTOS AGRÍCOLAS}

Para a compreensão do estudo do estabelecimento agrícola segundo a abordagem sistêmica, faz-se necessário ponderar sobre algumas definições e conceitos que são básicos para sua descrição e a caracterização. $O$ estabelecimento pode ser definido como sendo o "objeto" resultante da interação do sistema social com o sistema natural. Assim, o estabelecimento, como unidade de produção agrícola pode ser concebido como um sistema composto de um conjunto de elementos em interação (sistemas de cultivo e/ou criação e/ou transformação), influenciado pelos objetivos do agricultor/produtor rural e de sua família (sistema social), aberto e em interação com o meio externo (econômico, físico e humano).

A unidade de produção agrícola é, neste sentindo, um sistema dinâmico e aberto ao ambiente externo (ambiental, econômico, social). A partir desta definição, 
pode-se delimitar, de maneira clara e precisa, o objeto de estudo e de análise e sua inserção e articulação com o ambiente externo (MIGUEL, 2009).

Em um estabelecimento, o agricultor e sua família praticam um sistema de produção, que pode ser definido como o conjunto de produções vegetais e animais e de fatores de produção (capital, terra e trabalho), gerido pelo agricultor e sua família com vistas a satisfazer seus objetivos (MENDONÇA, 2014).

O estudo do sistema de produção se articula em torno do funcionamento de um estabelecimento agrícola, sob o ângulo de uma combinação organizada, com certa coerência de diversos subsistemas produtivos: sistemas de cultivo, sistemas de criações, sistema de transformações (BONNAL et al.,1994).

O sistema de cultivo consiste na descrição dos mesmos (e de seus itinerários técnicos específicos) que pode ser definido pelos tipos de cultivos, pela ordem de sucessão na parcela, assim como pelo itinerário técnico implementado em cada cultivo. Por sua vez, o sistema de criação consiste na combinação dos diferentes modos de condução (ou manejos) aplicados às diferentes categorias de uma espécie animal.

A imensa complexidade que envolve o processo de produção em uma unidade de produção agrícola exige uma aproximação progressiva. Inicialmente, busca-se delimitar e descrever os diferentes sistemas de criação e de cultivo, colocando em evidência suas particularidades e eventuais relações de troca e reciprocidade, logo, nesse sentido para a compreensão dos mecanismos de funcionamento e gestão de uma unidade de produção, considera-se imprescindível conhecer o comportamento do agricultor, explicar suas decisões passadas e presentes e buscar prever as decisões que ele tomará frente a mudanças em sua situação e ambiente (MIGUEL, 2009).

\section{MATERIAL E MÉTODOS}

O trabalho foi desenvolvido de outubro de 2013 a fevereiro de 2015 no âmbito de 10 assentamentos da reforma agrária, localizados em Unaí - Minas Gerais, contemplados pelo contrato 03/2011 de prestação de serviço de Assessoria Técnica, Social e Ambiental (ATES) firmado entre o Instinto Nacional de Colonização e Reforma Agrária (INCRA / SR 28 DFE) e a Cáritas Diocesana de Paracatu.

A metodologia adotada e descrita a seguir tem como referência os trabalhos de GASTAL et al. (2002; 2003) e ZOBY et al. (2003) (Figura 1). Foram utilizados dados secundários, obtidos através dos Planos de Recuperação dos Assentamentos (PRA), a fim de se ter uma visão inicial dos assentamentos. 
Figura 1 - Representação esquemática da metodologia utilizada (Adaptado de GASTAL et al. 2003, ZOBY et al. 2003 e GASTAL et al. 2002).

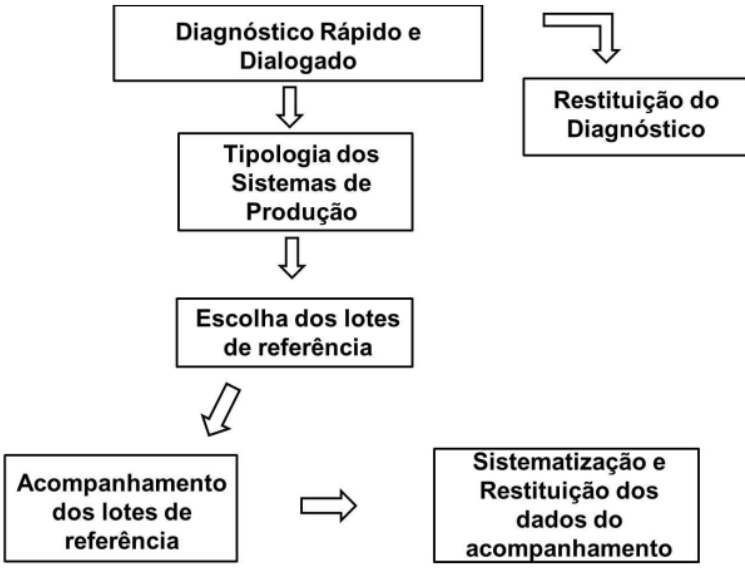

O objetivo da coleta dessas informações foi identificar as características do município que poderá influenciar na configuração dos sistemas de produção dos assentamentos.

Deu-se ênfase especial ao aspecto de solo, visto que sua variabilidade constitui uma das principais causas da diversidade do meio natural e a influência de maneira significativa nos modos de exploração dos sistemas de produção. Foram realizadas visitas individuais com aplicação de questionários específicos para o Diagnóstico Rápido e Dialogado (DRD) no período de novembro de 2013 a janeiro de 2014 em 390 famílias, o que corresponde a 75\% do total das famílias dos assentamentos (Tabela 1).

Tabela 1 - Identificação dos assentamentos entrevistados.

\begin{tabular}{lccc}
\hline Assentamento & № de Famílias & Assentamento & № de Famílias \\
\hline Campo Verde & 40 & Canabrava & 21 \\
\hline Curral do Fogo & 138 & Paraíso & 81 \\
\hline Renascer & 45 & Vazante & 63 \\
\hline Nova Califórnia & 49 & Papamel & 28 \\
\hline Santa Clara & 43 & Divisa Verde & 15 \\
\hline
\end{tabular}

O diagnóstico consistiu no conhecimento, análise e interpretação dinâmica dos sistemas de produção, recursos naturais, e organização social (assentamento). No questionário foram abordados os seguintes itens, considerando a safra 2012/2013:

Mão de obra: composição familiar e caracterização dos tipos de mão de obra empregados;

Cultivos: lista de cultivos, suas respectivas áreas, produção e o destino dessa produção (consumo familiar, comercialização, consumo animal, entre outros);

Rebanho: bovinos, suínos e aves. Descrição do sistema de criação e o destino dessa criação (consumo familiar, comercialização, consumo animal, entre outros); 
Fonte de ingressos monetários: ingressos da produção e locais de venda;

Fonte de ingressos externos: benefícios previdenciários (aposentadoria por idade e invalidez, auxílio doença, auxílio maternidade, pensão por morte), bolsa família, venda de mão de obra, aluguel de pasto, prestação de serviço, entre outras;

Despesas: principais produtos comprados para a exploração do estabelecimento e manutenção da família e locais de aquisição desses produtos.

O diagnóstico foi complementado com as seguintes informações: Sistemas de Produção: Destino da produção; Produtos comercializados; Formas de comercialização; Mercados dos produtos; Mercado de trabalho: Ocupação/emprego e desocupação/desemprego no assentamento.

Ressalta-se que antes da aplicação dos questionários, foi realizado um treinamento com a equipe, com o objetivo de padronizar a forma de aplicar esse instrumento na coleta de dados. Para o tratamento dos dados em fevereiro de 2014, foi criada uma base no Microsoft Excel.

Após as visitas e realização dos questionários, foram realizados no período de março de 2014, uma oficina de restituição em cada assentamento, para que os produtores avaliassem os resultados obtidos. Paralelo a isso elaborou-se a tipologia dos sistemas de produção dos assentamentos. O tratamento de dados para elaboração da tipologia de sistemas de produção constituiu, primeiramente, na caracterização da lógica geral de funcionamento desses sistemas.

De maneira geral, a lógica de diferenciação das unidades de produção em regime de economia familiar fundamenta-se na gestão da mão de obra familiar e na busca de estratégias que garantam a continuidade da unidade produtiva. A escolha dos critérios para identificar os tipos de unidade de produção estabeleceu as variáveis que melhor representava essa lógica.

Neste contexto, de acordo com as informações levantadas no diagnóstico levou-se em consideração para a tipologia as seguintes variáveis:

-Variáveis que descrevem a composição da renda da unidade de produção;

-Variáveis que apresentem o núcleo familiar: número de unidades de trabalho homem (UTH) da família e o número de dependentes da propriedade;

- Variáveis que permitem entender a resolução de problemas relativos aos desequilíbrios de mão de obra: tipo de mão de obra contratada e venda de força de trabalho. As práticas de troca de dia, contratação de mão de obra temporária ou permanente podem mostrar diferenças de recursos financeiros entre as unidades de produção;

- Variáveis que registrem formas de desenvolvimento de atividades de prestação de serviço e a presença de um salário não agrícola.

O cruzamento da tipologia de unidades de produção e das informações referentes as variáveis originaram uma matriz resumindo as principais situações existentes. Essa matriz foi feita em março de 2014 e é a base para a escolha dos estabelecimentos de referência componentes da rede.

A escolha dos estabelecimentos foi um processo de diálogo e negociação com os beneficiários e ocorreu no mês de março de 2014. Foram novamente discutidas as informações sobre a diversidade das unidades de produção, a necessidade de maior conhecimento sobre o funcionamento dessas unidades, os objetivos da rede e os resultados que ela deve gerar para beneficiar os demais 
agricultores, a importância da representatividade da rede e o perfil necessário aos seus integrantes. O objetivo dessa estratégia foi garantir que esta escolha fosse feita pelos assentados, gerando maior comprometimento entre os integrantes da rede, os técnicos e o grupo.

Após a tipificação dos sistemas de produção, foi realizado a caracterização de um dos sistemas predominante.

\section{RESULTADO E DISCUSSÃO}

Definiu-se escolher a tipologia mais representativa no sistema (Tabela 2) e iniciou-se a caracterização de uma propriedade que se enquadra neste padrão de tipologia.

Tabela 2 - Características da Tipologia Avaliada

\begin{tabular}{|c|c|}
\hline & Tipologia do sistema predominante \\
\hline Produção de leite & Abaixo de 200 litros dia \\
\hline Gado & Entre 1 a 30 vacas (Lotação Média de 19 U.A) \\
\hline Venda de Leite & Abaixo de 200 litros de leite por dia. \\
\hline Agricultura & $\begin{array}{l}\text { Poucas famílias vendem produtos agrícolas. A maioria dos } \\
\text { estabelecimentos possui em média } 2,0 \mathrm{Ha}-1 \text { de lavouras. }\end{array}$ \\
\hline Renda & $\begin{array}{l}\text { Vendem de } 0,80 \text { a } 170 \text { litros de leite por dia. } \\
\text { Todas as famílias recebem rendas externas*. Nenhuma família } \\
\text { vende mão de obra. } \\
\text { Nenhuma família vende frangos e ovos. Há, em alguns casos, a } \\
\text { venda de produtos oriundos de outras criações e atividades }{ }^{* *} \text {. }\end{array}$ \\
\hline \multicolumn{2}{|c|}{$\begin{array}{l}\text { *bolsa escola, aposentadoria, auxílio doença, salário, aluguel de imóveis, prestação de serviço, } \\
\text { aluguel de pasto, gado à meia, e outras. } \\
\text { **demais criações animais, além de industrialização caseira (farinha de mandioca, polvilho, } \\
\text { rapadura, melado de cana, e doces) e venda de produtos oriundos de atividades manuais: corte } \\
\text { e costura, bordado, crochê, etc. }\end{array}$} \\
\hline
\end{tabular}

Na figura 2 demostra que $89 \%$ da área total do estabelecimento é ocupada com pastagem formada, $7 \%$ com sorgo para silagem e os outros $4 \%$ com outras atividades e benfeitorias. Portanto, $98,9 \%$ da área total são utilizadas para exploração pecuária, demonstrando que a criação de gado é o subsistema de criação que mais se destaca no estabelecimento. 
Figura 2 - Estrutura do sistema de produção estudado.

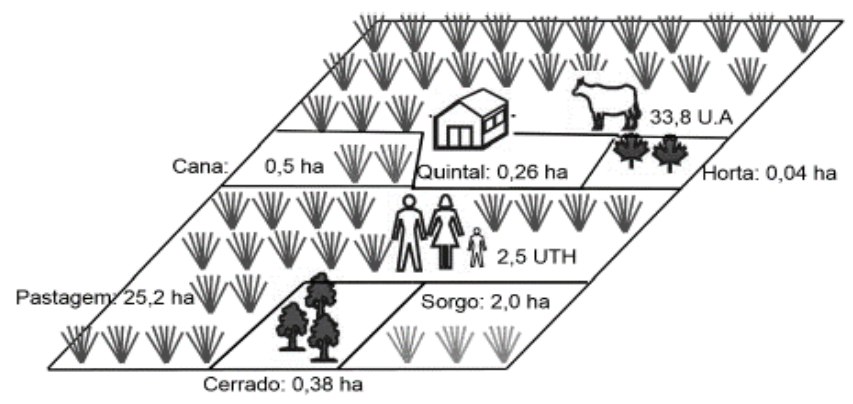

Esses dados corroboram com estudos feitos por Zoccal et al. (2003), onde destaca as pastagens cultivadas como a principal ocupante dos solos para alimentação volumosa dos rebanhos dos agricultores familiares da zona da mata mineira. A maior parte das lavouras é utilizada para produção de volumoso para os bovinos. Informações que são confirmadas por Gastal et al. (2003), onde no trabalho desenvolvido nos assentamentos rurais do município de Unaí, identificou-se que as lavouras cumpriam uma função complementar, mas fundamental, relacionada à alimentação da família e das criações, destacando-se o milho e a cana.

O rebanho bovino é composto por 40 animais, o que corresponde a 33,8 U.A., que também tem uma função de poupança. Essa composição do rebanho fortalece e justifica a participação do leite, em relação às demais rendas identificadas nas áreas estudadas.

Verifica-se também que a família está incorporando, progressivamente, equipamentos utilizados no desempenho da atividade pecuária, como triturador para preparo do volumoso e a carroça para transportar o leite produzido. Destaca-se o uso da mão de obra familiar em todas as atividades, demandando em média 18,2 dias de trabalho/pessoa/mês. As atividades (Figura 3) relacionadas a pecuária ocupam $47 \%$ da mão de obra familiar, $19 \%$ com atividades gerais, 13,17\% estão relacionadas a agricultura, $6 \%$ na transformação de produtos (queijo e doces) e $6 \%$ em atividades fora do estabelecimento. 
Figura 3 - Uso da mão de obra familiar mensal no ano fiscal.

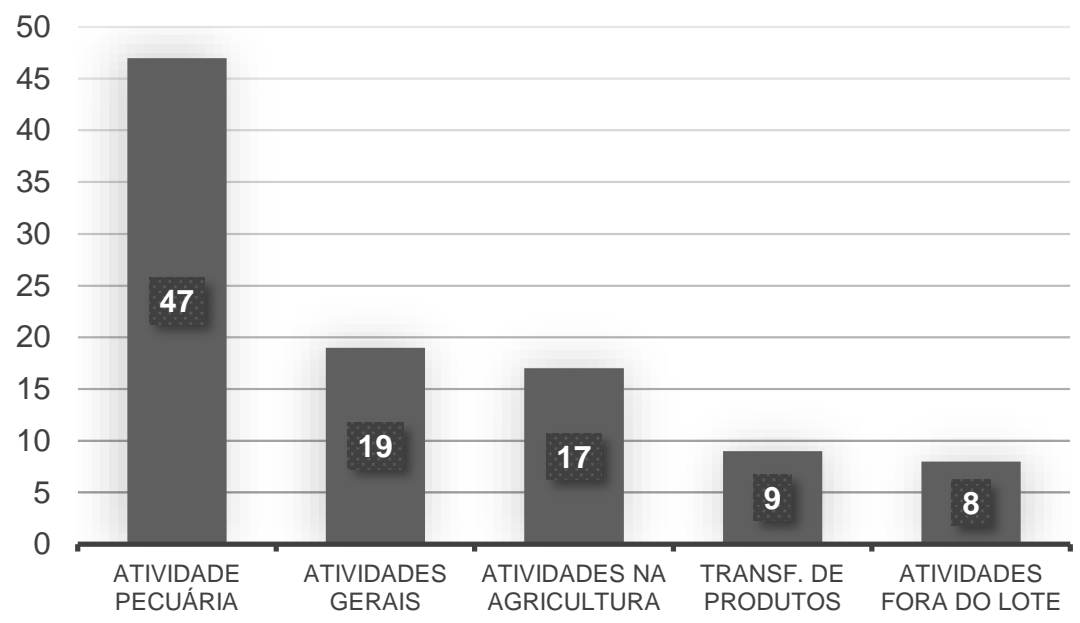

Segundo Menezes et al. (2005) o conhecimento do uso da mão-de-obra familiar, dentro do sistema de produção e a sua participação no conjunto de atividades desenvolvidas pela família é de suma importância para estabelecer políticas públicas para aumentar a sua sustentabilidade, aumentar a renda familiar e subsídio na gestão dos estabelecimentos familiares.

No estabelecimento a atividade agropecuária é destinada ao consumo familiar e para gerar renda. Observa-se na Figura 4, que a reprodução socioeconômica é garantida pela venda de leite in natura, associada com venda de queijo, hortaliças e renda não agrícola (aposentadoria). A família comercializa, em pequena escala, produtos como doces, artesanato, suínos e ovos por meio de intermediário de produtos. Este sistema de produção se caracteriza, principalmente pelo conjunto de elementos em interação, dentro de um quadro de atividades agrícolas e não agrícolas, visando a obtenção de produções variadas na criação de bovinos, suíno, artesanato e hortaliças.

Mesmo com a diversificação de produtos, observa-se que a renda proveniente do leite é a mais significativa, proporcionando a família a maior fonte de renda entre as demais observadas, correspondendo a $50 \%$ da renda total.

Neste estabelecimento a produção média diária de leite é de 97,1 L/dia, destes $95 \%$ são destinados à comercialização in natura para a Cooperativa Agropecuária de Unaí - CAPUL Itda, $2 \%$ para consumo familiar, $2 \%$ da produção é para transformação de produtos (queijo e doces) e 1\% para comercialização in natura para intermediário. 
Figura 4 - Participação das atividades desenvolvidas pela família na composição da renda no ano fiscal.

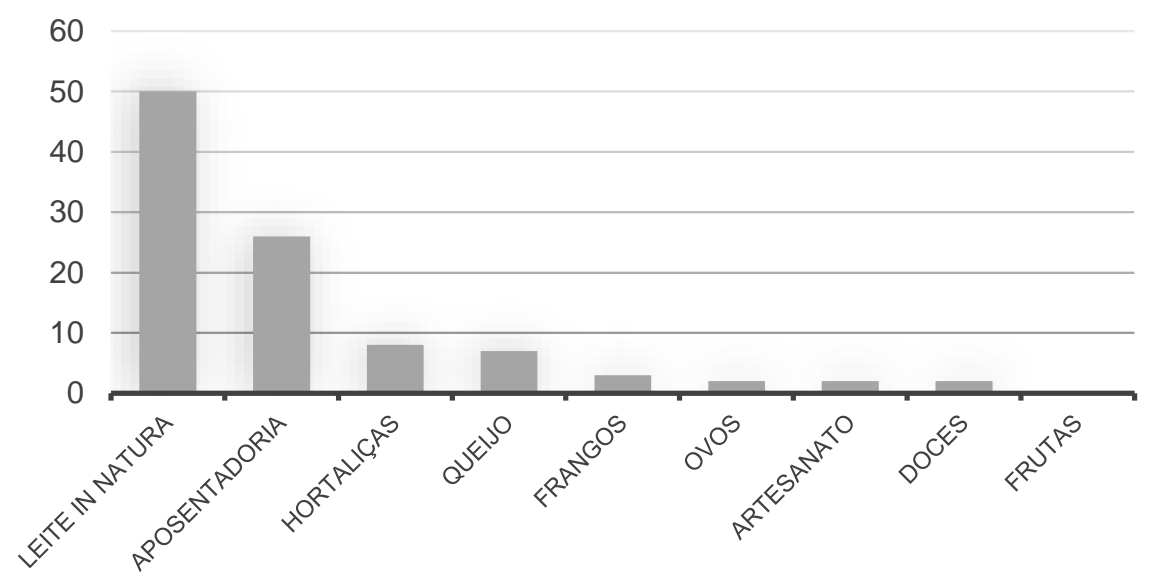

A produção média por vaca é de 9,7 litros ao dia e de acordo com o censo 2013 do Instituto Brasileiro de Geografia e Estatística - IBGE (2015) essa produção está dentro da média municipal.

Figura 5 - Relação das principais despesas da produção no ano fiscal.

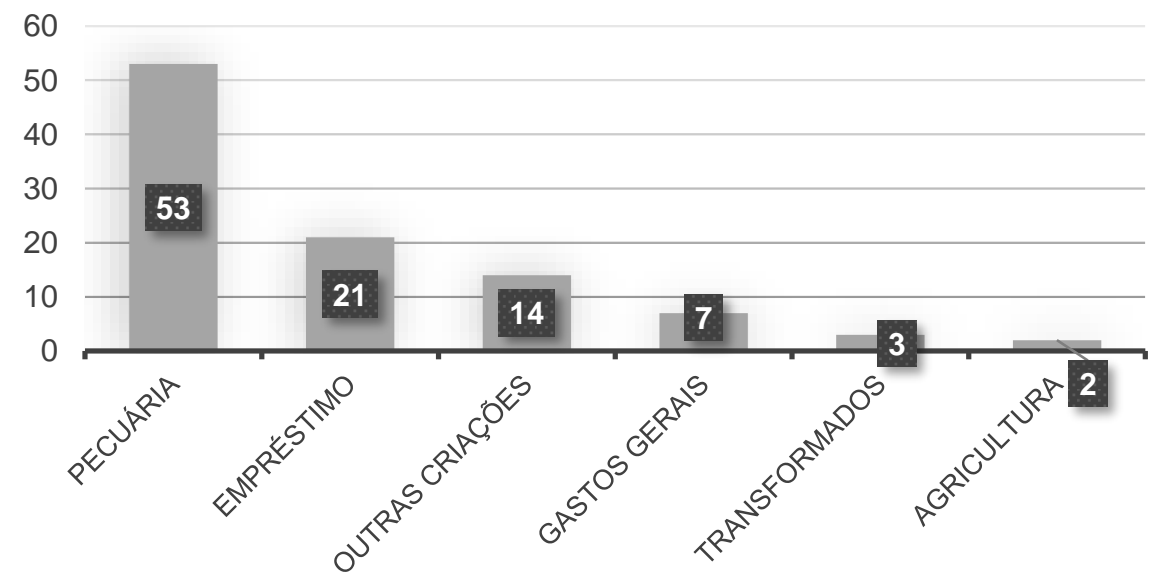

Os principais gastos do estabelecimento são despesas com a atividade pecuária (53\%), 21\% para pagamento de empréstimo bancário e 14\% com pequenos animais (Figura 5). Impressiona o fato de que $95 \%$ dos gastos com a pecuária são com aquisição de ração bovina, mostrando uma forte dependência do sistema de produção de insumos de fora da propriedade. De acordo com Couto et al. (2018), maior parte dos produtores leiteiros, realizam uma contabilidade rudimentar, não 
sendo percebidos certos custos indiretos tais como a depreciação., e tal situação leva a uma superestimação do "lucro" obtido, dando uma sensação, falsa, de boa saúde financeira na atividade, podendo, no longo prazo, levar o produtor a falência, à medida que se capital imobilizado é consumido.

\section{CONSIDERAÇÕES FINAIS}

A caracterização de um sistema de produção demonstra ser uma importante ferramenta, pois permite conhecer a realidade socioeconômica da família, apresentando assim, suporte aos técnicos responsáveis pelo acompanhamento da mesma, propor alternativas tecnológicas compatíveis com os riscos, com a força de trabalho disponível e com os recursos financeiros da família. Isso é confirmado pelos resultados socioeconômicos do sistema de produção após a adoção das tecnologias apropriadas propostas pelos extensionistas em conjunto com os beneficiários. Estes foram positivos no primeiro ano fiscal e contribuíram para melhoria dos resultados do sistema de produção como um todo.

O enfoque sistêmico ofereceu aos técnicos uma visão integrada do sistema de produção, e do seu processo de gestão. E foi também uma ferramenta para planejar e montar sistemas que produzam resultados.

Os resultados alcançados no futuro, permitirá a geração das referências técnicas e metodológica para profissionais que prestam serviço de Assessoria Técnica, Social e Ambiental.

\section{REFERÊNCIAS}

BONNAL, $P$. et al. 0 papel da rede de fazendas de referência no enfoque de pesquisa-desenvolvimento: Projeto Silvânia. Planaltina: EMBRAPA-CPAC, 1994. $31 \mathrm{p}$.

CHRISTOFOLETTI, A. Análise de sistemas em geografia. São Paulo: Hucitec, 1979.

COUTO, M. J.; REIS, J. D.; LIMA, A. L. R. Análise econômico-financeira da produção leiteira: um estudo de caso no Centro-Oeste mineiro. Extensão Rural, v.25, n. 1, p. 41-59, jan./mar. 2018.

GASTAL, M.L. et al. Método participativo de apoio ao desenvolvimento sustentável de assentamentos de reforma agrária. Planaltina, DF: EMBRAPA Cerrados, 2002.

GASTAL, M. L. et al. Projeto Unaí: diagnostico rápido e dialogado de três assentamentos de reforma agrária. Planaltina, DF: EMBRAPA Cerrados, 2003.

IAPAR. Avaliação da estratégia global de paraná-Rural: Programa de Manejo e Conservação do Solo em Microbacias Hidrográficas. Curitiba, 1993. 115p. Convênio do Governo do estado do Paraná, BIRD.

IBGE. Censo agropecuário 2013.2 Disponível em: http://www.sidra.ibge.gov.br/bda/pesquisas/ppm/default.asp?o=27\&i=P. Acesso em: 02 jul. 2018. 
MANGGINI, T. R. T. Campesinato e agronegócio: a experiência educativa do assentamento Eldorado dos Carajás Unaí/MG. 2012. 176 p. Dissertação (Mestrado em Educação) - Faculdade de Educação, Universidade de Brasília, Brasília.

MAXIMIANO, A. C. A. Teoria geral da administração. São Paulo, MAKRON BOOKS, 1993.

MENDONÇA, A.P.B. Inovação técnica em sistema de produção da agricultura familiar: impactos no funcionamento e nos resultados econômicos de uma unidade de produção familiar. (Graduação em Agronomia) - Faculdade de Ciências e Tecnologia de Unaí, Unaí, 2014.

MENEZES, A. J. E. A.; SANTANA, A. S.; MENDES, F. A. T. Uso da mão-de-obra familiar nos sistemas de produção do projeto de assentamento agroextrativista praialta e piranheira, município de Nova Ipixuna - Pará. In: XLIII CONGRESSO BRASILEIRO DE ECONOMIA E SOCIOLOGIA RURAL. Instituições, Eficiência, Gestão e Contratos no Sistema Agroindustrial. SOBER: Anais... Ribeirão Preto, 2005.

MIGUEL, L. A. (Org.). Dinâmica e diferenciação de sistemas agrários. Porto Alegre: Ed. da UFRGS, 2009. Série Educação a Distância. Disponível em: http://http.sead.ufrgs.br/Publicacoes/derad002.pdf. Acesso em: 15 dez. 2018.

PINHEIRO, M. E. F. Eficiência da produção familiar de leite: identificando benchmarks. 2000. 155p. Dissertação (Mestrado) - Faculdade de Agronomia e Medicina Veterinária, Universidade de Brasília, Brasília.

PREFEITURA MUNICIPAL DE UNAÍ. Unaí. Disponível em: http://www.prefeituraunai.mg.gov.br/pmu/index.php/unai-um-municipio-pronto-parao-futuro.html. Acesso em: 06 set. 2018.

SCHMITZ, H. et al. Métodos participativos e agricultura familiar: atualizando o debate. In: SEMANA DA CAPRINOCULTURA E OVINOCULTURA BRASILEIRAS, 4., 2004, Sobral. Anais... Sobral: Embrapa Caprinos, 2004. 26 p. 1 CD-ROM.

SOUSA, D. N. et al. A dinamização dos assentamentos rurais para o desenvolvimento econômico do Noroeste de Minas Gerais. Revista de C. Humanas, Viçosa, v.2, n.1, p.87-97,jan./jun. 2011.

TORRES, A. L. Formação social e mediação: a luta pela terra e a consolidação dos assentamentos rurais no município de Unaí - MG. 2000.149 p. Dissertação (Mestrado em Extensão Rural), Universidade Federal de Viçosa, Viçosa.

ZOBY, J. L. F. et al. Transferência de tecnologia, agricultura familiar e desenvolvimento local: a experiência do Projeto Silvânia. Planaltina, DF: EMBRAPA Cerrados, 2003.

ZOCCAL, R.; SOUZA, A. D.; GOMES, A. T.; LEITE, J. L. B. Produção de leite na agricultura familiar. Zona da Mata de Minas Gerais. 2003. 